\title{
SOFTWARE PIRACY: EXPLORING AWARENESS OF THE LAW AS A DETERMINANT OF SOFTLIFTING ATTITUDE AND INTENTION
}

\author{
Pamela A. Dupin-Bryant, Utah State University, pam.dupin-bryant@usu.edu
}

\begin{abstract}
Software piracy, the unauthorized copying of computer software, poses a significant threat to the computer industry. In recent years, progress has been made to reduce software piracy. However, computer software is greatly susceptible to theft and software vendors worldwide lost a staggering $\$ 50$ billion due to piracy this past year [4]. This paper outlines research in progress that will provide insight into software piracy attitude and intention. The purpose of the research is to investigate whether awareness of piracy laws is an antecedent to attitudes and intention to softlift. This study promises to make several important contributions. The work should complement the knowledge base on software piracy prevention and may demonstrate the value of the factor Legal Awareness in theoretical models of the antecedents that influence softlifting attitude and intention. Results may also prove helpful to information systems professionals and educators in implementing measures to discourage software piracy.
\end{abstract}

Keywords: Software Piracy, Ethics, Softlifting, Intellectual Property Rights, and Computer Crime.

\section{INTRODUCTION}

Software piracy, the unauthorized copying of computer software, poses a significant threat to the computer industry. Intellectual property, such as computer software, is highly vulnerable to theft. Although, progress has been made in recent years to reduce software piracy, losses to software vendors grew by more than $\$ 5$ billion in 2008 , with total worldwide loss over $\$ 50$ billion [4]. Reducing software piracy would have a positive impact on the economy. If the U.S. alone were to reduce software piracy by 10 percent over the next four years, the International Data Group (IDC) believes the result would be (a) \$41 billion in economic growth; (b) $\$ 6.7$ billion in additional tax revenues for federal, regional, and local governments; and (c) the creation of over 32,000 new jobs. In countries with higher piracy rates, the impact would be even greater [9].

According to the World Intellectual Property Organization (WIPO), intellectual property law is intended to protect creators and other producers of intellectual goods and services [22]. Of the two branches of intellectual property identified by WIPO, violation of copyright is the primary interest in this study. Software piracy occurs when computer software is copied without permission from the owners, in direct violation of copyright and intellectual property rights legislation (e.g. the U.S. No Internet Theft Act, the Digital Millennium Copyright Act, and the Digital Theft Deterrence and Copyright Damages Improvement Act). Moores and Chang [14] suggest that although legislation is in place, enforcement can be challenging; they suggest there is a need to "explore alternative ways to prevent infringement of intellectual property rights and theft of digital goods" (p. 168).

The Software and Information Industry Association [20] identifies ten ways individuals intentionally or unintentionally pirate software, this study is concerned with softlifting which "occurs when a person purchases a single licensed copy of a software program and loads it on several machines, in violation of the terms of the license agreement" ( $p$. 3). A typical example of softlifting is sharing a single-user license copy of a software program with friends and coworkers.

The motivation to pirate software is often framed on a national or international level. This study will investigate the problem at an individual level and explore the relationship between awareness of the law, attitude towards softlifting, and intention to softlift. Given the current world economic climate, software piracy has negative consequences for both global and local economies [4]. Exploring awareness of the law as a determinant of softlifting attitude and intention will provide insight into this prevalent issue and may help in the development of measures to reduce this wide-reaching problem.

This work in progress paper is organized as follows. Theoretical background and research hypotheses are presented along with the research model. Since this paper outlines research in progress a detailed methodology section is presented prior to concluding remarks. 


\section{THEORETICAL BACKGROUND AND RESEARCH HYPOTHESES}

This study seeks to investigate the relationship between legal awareness and software piracy attitude and intention. Software piracy can be conceptualized as a behavior [13]. Behavioral intention research is often studied holistically using comprehensive models. Yet, looking at intention to pirate software in this manner can be crippling. Harrison, Mykytyn, and Riemenschneider [8] suggest that information systems research focusing on behavioral intention should refine and tailor a theory to fit a specific research context. Liang and Yan [12] recommend the use of specific models to develop further understanding of pirating behaviors. Recent studies on software piracy have customized accepted behavioral intention models and have concentrated on a subset of constructs [7, 13, 15, 17, 19, 21, 23]. Many researchers have framed their work within the area of attitude and intention to pirate software $[7,10$, $11,16,17,18,19,22]$.

Ajzen [1] developed a behavioral intention model that is widely cited and tested empirically. This study focuses on the attitude component of Ajzen's Theory of Planned Behavior (TPB). Behavioral beliefs according to the TPB [2] refer to the beliefs about consequences of a particular behavior; they "produce a favorable or unfavorable attitude toward the behavior" (p. 1). This study focuses on one such variable, behavioral beliefs related to Awareness of the Law. As with Ajzen's comprehensive model [3], this model suggests attitude toward the behavior leads to behavioral intention. Intention is defined as the cognitive representation of an individual's subjective probability to perform a given behavior and in Ajzen's model [3], intention is assumed to be the immediate antecedent to behavior. This study will not examine actual behavior since examining piracy intentions rather than the actual behavior is considered an acceptable and preferable research approach since people tend to understate their actual illegal and/or unethical behavior in self report survey methodologies [19].

Figure 1 summarizes the research model. Variables included in the model, as antecedents of softlifting intention, are described below along with the associated research hypothesis. Hypotheses are stated in alternative form.

Figure 1. Research Model

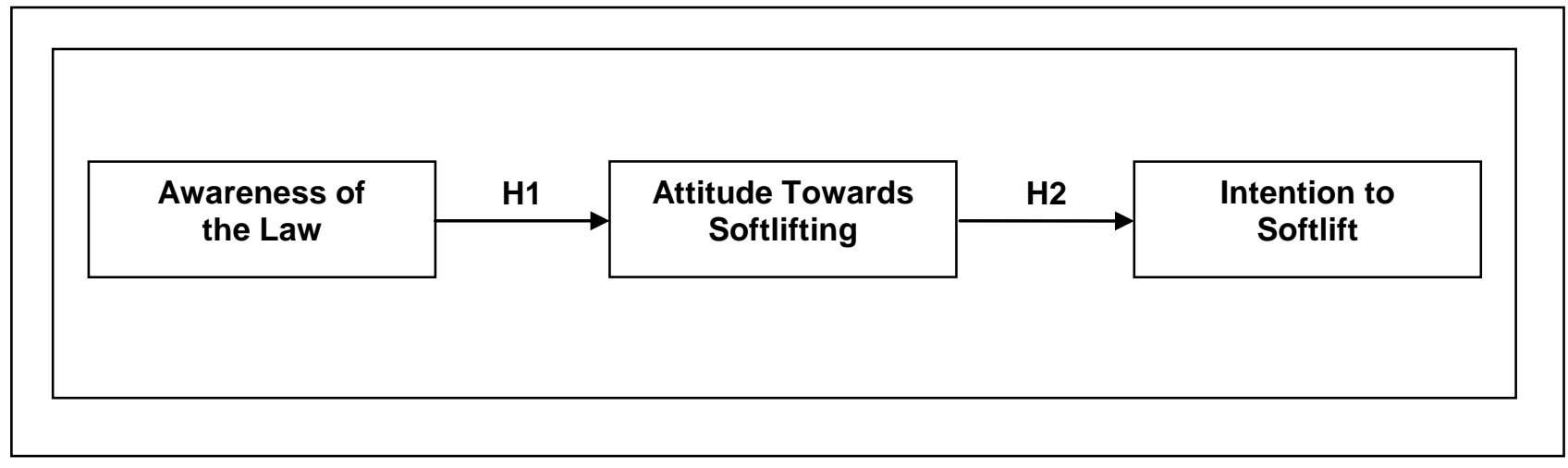

\section{Awareness of the Law}

Derived from the belief that many individuals have a vague understanding of the restrictions and penalties for copying software, Awareness of the Law is defined as the degree to which a person is aware of the legal consequences of software piracy. Many have hypothesized that as individuals become more knowledgeable about copyright laws and the associated punishment/consequences, attitude toward software piracy should become less positive [7, 15]. Moores, Nill, and Rothenberger [15] suggest "in order to change a person's attitude toward software piracy, the individual must understand what software piracy is, and be aware of the likelihood and severity of punishment of engaging in software piracy" ( $p$. 83). Several recent studies have looked at awareness and knowledge of laws and the negative consequences of copying software illegally. In one study, awareness of the law was found to have a negative relationship to attitude toward software piracy in a school setting [7]. Another study found knowledge of the social, legal, and economic consequences of software piracy led to an awareness of punishments and fear of legal consequences which had significant impact on attitude and consequently 
behavior [15]. This study will build upon these works and investigate the relationship between awareness of the law and attitude toward softlifting.

\section{Hypothesis 1 (H1): The more an individual is aware of laws regarding software piracy, the less favorable his or her attitude will be toward softlifting.}

\section{Attitude}

The theory of planned behavior contends that attitude toward the behavior leads to behavioral intention [3]. Liang and Yan [12] state "attitude is generally defined as a psychological tendency of evaluating a specific entity and generating certain favorable or unfavorable responses" (p. 119). In a review of software piracy literature, Liang and Yan [12] found extensive research suggesting attitude toward piracy is a predictor of piracy intention. Recent studies also support the assertion that software piracy attitude is a determinant of software piracy intention $[7,16,17$, $18,19]$. This study underscores previous research by exploring the relationship between attitude toward softlifting and intention to softlift.

Hypothesis 2 (H2): The more favorable an individual's attitude is toward softlifting, the greater his or her intention will be to softlift.

\section{METHODOLOGY}

This study seeks to gather evidence from undergraduate business students that will lead to general conclusions about relationships between awareness of the law, softlifting attitude, and intention to softlift using a correlational, quantitative research design.

\section{Sampling Procedure}

Undergraduate students taking management information systems (MIS) courses at a public university in the western United States will comprise the accessible population. In order to facilitate the comparison with prior software piracy research, the sampling frame will include students from undergraduate MIS courses. Students are often used in software piracy research since they readily engage in software piracy $[14,15,17]$. Studies suggest that student participation in softlifting research is reasonable since attitude toward softlifting is shaped prior to entry into the workforce and these attitudes will likely follow the students into the workforce [5,
7]. Bivariate correlations between demographic data and dependent variables will be calculated to explore possible bias resulting from the use of students. A sample size of 200 was determined for this study. The sample size is based on power analysis and by reviewing methodologies of related research. To insure the sample size will be reached the study will assume a $70 \%$ response rate and thus approximately 300 individuals will be selected to participate.

\section{Data Collection}

Participants will be solicited from undergraduate MIS classes. With cooperation of professors, questionnaires will be distributed during normal class sessions. Class lists will be checked to ensure minimal overlap. Also, students will be asked not to complete the survey if they have already done so in another class. Selected participants will be asked to complete a survey which includes demographic information and a software copying section. Since the sample frame was carefully selected and based on relevance to the research goals, the anticipated salience of the survey's content to respondents is high. Information about the students who completed the survey will be provided to make it easier to identify the appropriate group to whom inferences apply.

\section{Instrumentation}

A research questionnaire will be used to collect data for this study. The instrument was carefully developed based on Ajzen's Theory of Planned Behavior $[1,2,3]$ and by following the recommendations in Constructing Theory of Planned Behaviour Questionnaires: Manual for Researchers [6]. Items will be interspersed prior to data collection and $25 \%$ of the survey questions will be reversescaled in order to protect against positive response bias. The survey items use 7-point likert scales. As suggested by Goles et al. [7] softlifting is labeled copying software to avoid a negative connotation. The term copying software is clearly defined to participants at the beginning of the survey. The awareness of the law measures (strongly certain to strongly uncertain) were developed using scales designed by Goles et al. [7]. The attitude scale was developed based on the scales of Lending and Slaughter [10] and in accordance with the TPB instrument development manuals $[2,6]$. The behavioral intention scale was developed using scales designed by Limayem et al. [13]. Appendix A lists the items in each scale. 


\section{Data Analysis}

Various techniques will be used to analyze the data, including reliability analysis and factor analysis to assess construct validity. Correlational analysis will be used to investigate relationships between awareness of the law, attitude, and intention. A card sort has been conducted on ten respondents to test face validity. Results will be triangulated with exploratory factor analysis performed on approximately fifty students participating in a pilot test.

\section{CONCLUSION}

This study promises to make several important contributions to theory and education. This study will contribute new knowledge to the field and enhance the educational quality of MIS programs. This work should demonstrate the importance of continued use of the factor Legal Awareness in theoretical models of the antecedents that influence softlifting attitude and intention. If awareness of the law is found to be an antecedent of softlifting attitude and intention, software piracy researchers should consider this factor in future research. On the other hand, negative results may help researchers improve the fit of their models.

This study will survey management information systems students. The academic community is responsible for shaping the attitudes of these future information systems professionals and preparing them to become ethical, contributing members of the business world. Understanding student attitudes concerning illegal software copying behaviors may lead to thoughtful and innovative educational strategies to deal with this serious and pervasive problem.

\section{REFERENCES}

1. Ajzen, I. (1991). The theory of planned behavior. Organizational Behavior \& Human Decision Processes, 50(2), 179-211.

2. Ajzen, I. (2006a). Constructing a TPB questionnaire: Conceptual and methodological considerations. Retrieved March 2, 2010, http://www.people.umass.edu/aizen/pdf/tpb.meas urement.pdf

3. Ajzen, I. (2006b). Behavioral interventions based on the theory of planned behavior. Retrieved March 2, 2010, from http://people.umass.edu/aizen/pdf/tpb.interventio n.pdf
4. BSA. Business Software Alliance. (May, 2009). Sixth annual BSA and IDC global software piracy study. Business Software Alliance, Washington, D.C.

5. Cheng, H., Sims, R., \& Teegan, H. (1997). To purchase or pirate software: An empirical study. Journal of Management Information Systems, 13, 49-60.

6. Francis, J., Eccles, M., Johnston, M., Walker, A., Grimshaw, J., Foy, R., Kaner, E., Smith, L., \& Bonnetti, D. (2004). Constructing questionnaires based on the theory of planned behavior. Centre for Health Services Research, New Castle, United Kingdom.

7. Goles, T., Jayatilaka, B., George, B., Parsons, L., Chambers, V., Taylor, D., \& Brune, R. (2008). Softlifting: Exploring determinants of attitude. Journal of Business Ethics, 77, 481-499.

8. Harrison, D., Mykytyn, P., \& Riemenschneider, C. (1997). Executive decisions about adoption of information technology in small business: Theory and empirical tests. Information Systems Research, 8, 171-194.

9. IDC. International Data Group. (January, 2008). Profile: The economic benefits of lowering pc software piracy, United States. Sponsored by Business Software Alliance, Framingham, MA.

10. Lending, D., \& Slaughter, S. (1999).

Understanding differences in ethical beliefs and behaviors toward software copying: The effects of organization culture, in Ritu Agarwal and Jayesh Prasad (Eds.) Proceedings of the Association for Computing Machinery Special Interest Group of Computer Personnel Research Conference, April 8-10, New Orleans, Louisiana, USA, ACM, 253-260.

11. Lending, D., \& Slaughter, S. (2001). Research in progress: The effects of ethical climate on attitudes and behaviors toward software piracy, in Mark Serva (Ed.) Proceedings of the Association for Computing Machinery Special Interest Group of Computer Personnel Research Conference, San Diego, California, USA, ACM, 198-200.

12. Liang, Z., \& Yan, Z. (2005). Software piracy among college students: A comprehensive review of contributing factors, underlying processes, and tackling strategies. Journal of Educational Computing Research, 33(2), 115140.

13. Limayem, M., Khalifa, M., \& Chin, W. (2004). Factors motivating software piracy: A longitudinal study. IEEE Transactions on Engineering Management, 51(4), 414-425.

14. Moores, T., \& Chang, J. (2006). Ethical decision making in software piracy: Initial development 
and test of a four-component model. MIS Quarterly, 30(1), 167-180.

15. Moores, T., Nill, A., \& Rothenberger, M. (2009). Knowledge of software piracy as an antecedent to reducing pirating behavior. Journal of Computer Information Systems, 50(1), 82-89.

16. Peace, A., \& Galletta, D. (1996). Developing a predictive model of software piracy behaviour: An empirical study. Proceedings of the Seventeenth International Conference on Information Systems, December 16-19, Cleveland, Ohio, 209-222.

17. Phau, I., \& Ng, J. (2010). Predictors of usage intentions of pirated software. Journal of Business Ethics, 94(1), 23-37.

18. Rahim, M., Rahman, M., \& Seyal, A. (2000). Softlifting intention of students in academia: A normative model. Malaysian Journal of Computer Science, 13(1), 48-55.

19. Rahim, M., Seyal, A., \& Rahman, M. (2001). Factors affecting softlifting intention of computing students: An empirical study. Journal of Educational Computing Research, 24(4), 385405.

20. SIIA. The Software and Information Industry Association. (2009). What is piracy: The piracy problem. Retrieved February 9, 2009, from http://www.siia.net/piracy/pubs/WhatIsPiracy.pd $\mathrm{f}$

21. Tang, J., \& Farn, C. (2005). The effect of interpersonal influence on softlifting intention and behavior. Journal of Business Ethics, 56, 149-161.

22. WIPO. World Intellectual Property Organization. (2004). WIPO intellectual property handbook: Policy, law, and use ( $2^{\text {nd }}$ ed.), WIPO Publication no. 489(E), Geneva, Switzerland.

23. Workman, M., \& Gathegi, J. (2007). Punishment and ethics deterrents: A study of insider security contravention. Journal of the American Society for Information Science and Technology, 58(2), 212-222. 


\section{APPENDIX A. MEASURES}

The survey will contain the following definition of copying software.

The phrase copying software is intended to encompass these behaviors:

- You purchase a single license copy of a software program and load it on several machines.

- You purchase a single license copy of a software program and give copies to your friends, coworkers, or other students.

- Your friend, coworker, or other student provides you a copy of software.

- Your friend, coworker, or other student allows you to copy software.

The phrase copying software does not include:

- The making of a single backup copy, or

- The acquisition of shareware, freeware, or open-source software requiring no licensing or payment.

Measurement Items -7 point Likert scales

Awareness of the Law (Strongly Uncertain to Strongly Certain)

AL1 Copying software is illegal.

AL2 Anyone copying software can be sued.

AL3 Anyone copying software can be jailed.

AL4 Anyone copying software can be fined.

Attitude

My unauthorized copying of software would be:

\begin{tabular}{|l|l|}
\hline AT1 & Harmful - Beneficial \\
\hline AT2 & Good - Bad \\
\hline AT3 & Worthless - Useful \\
\hline AT4 & The right thing to do - The wrong thing to do \\
\hline Intention (Strongly Agree to Strongly Disagree) \\
\hline IN1 & I intend to copy software in the future. \\
\hline IN2 & I expect to copy software in the future. \\
\hline IN3 & I will likely copy software in the future. \\
\hline
\end{tabular}

